\title{
O periódico como objeto de estudo: uma análise de Bref, o jornal mensal do TNP de Vilar
} The journal as an object of study:
an analysis of Bref, the monthly journal of Vilar's TNP

Mariana Oliveira' 


\section{Resumo}

Este artigo traz uma análise de Bref, o jornal mensal do Teatro Nacional Popular (TNP), durante os anos em que Jean Vilar esteve à frente da companhia teatral francesa. O TNP é visto sob seis pontos fundamentais: relação com o público, missão de um teatro nacional, concepção humanista do teatro, ações para a democratização da cultura, mediação com o mundo escolar e dimensão educativa. $O$ texto pretende contribuir para a reflexão acerca da mediação teatral e da formação de espectadores, além de demonstrar o valor dos periódicos sobre teatro como objetos de pesquisa histórica.

Palavras-chave: Bref; Teatro Nacional Popular; Jean Vilar.

\section{Abstract}

This article presents an analysis of Bref, the monthly journal of the National Popular Theatre (TNP), during the years in which Jean Vilar led the French theatrical company. The TNP is seen under six key points: relationship with the public, mission of a national theater, humanist conception of theater, actions for the democratization of culture, mediation with the school world and educational dimension. The paper seeks to contribute to the reflection on theatrical mediation and spectators formation, as well as demonstrating the value of theater journals as objects of historic research.

Keywords: Bref; Popular National Theatre; Jean Vilar. 
Variados podem ser os propósitos dos periódicos sobre teatro: entre eles, o estímulo ao debate vivo entre pesquisadores, profissionais e amantes dessa arte. Isso faz dessas publicações, a exemplo desta que o leitor tem diante de si, objetos de grande atualidade e de valor relativamente efêmero. Por outro lado, com o tempo, elas podem ganhar novos significados, se vistas sob a perspectiva histórica. Nesse sentido, elas oferecem-se como verdadeiras fontes de investigação, contribuindo para a reconstituição do panorama teatral de uma época, ao revelar ideias, fatos, documentos, imagens, críticas, teorias e estéticas que dela fizeram parte. André Veinstein (1955) foi pioneiro neste gênero de abordagem em estudo sobre o "teatro de arte" europeu baseado na análise das publicações dirigidas por Antoine, Lugné-Poe, Copeau, Baty, Dullin e Jouvet. Sua obra inspirou novos caminhos metodológicos para a pesquisa historiográfica teatral².

Tendo como referência essa tradição de pesquisa, o presente artigo partirá da análise de Bref, o jornal mensal do Teatro Nacional Popular (TNP), para discutir alguns dos aspectos que marcaram a célebre companhia teatral francesa no período que vai do ano de 1956, quando a publicação foi lançada, ao de 1963, quando o ator e encenador Jean Vilar deixou a direção da trupe, fechando um ciclo em sua história. Ao mesmo tempo em que será resgatada a aventura teatral do TNP, imersa em seu contexto histórico, espera-se também estimular a reflexão sobre temas da atualidade ligados às possíveis relações entre artistas, público, Estado e educação. O texto buscará, assim, contribuir para um debate vivo, que tem se aprofundado com o recente interesse dispensado, no Brasil, à questão da mediação (Pupo, 2009; 2011) e da formação de espectadores (Desgranges, 2010).

Nesse debate, o exemplo histórico do TNP revela-se especialmente interessante por ter investido fortemente na formação e no contato regular com o público, cumprindo a missão de um teatro nacional subvencionado pelo Estado, comprometido com a meta da democratização da cultura. Segundo a famosa definição de Jean Vilar: "O TNP é, antes de tudo, um serviço público. Tal como a água, o gás, a eletricidade" (Vilar, 1975, p.173). A partir dessa ideia, os comentários sobre Bref e as citações dela extraídas, como se verá nas páginas a seguir, ajudarão a compor com mais detalhes o quadro geral que marcou a estrutura e o perfil da companhia teatral francesa.

\section{A relação com o público}

Criada inicialmente por uma associação de espectadores do TNP, Bref passou à responsabilidade da própria companhia a partir de dezembro de 1956. Seu intuito primordial era estabelecer uma ligação permanente com o público, inclusive o associativo, por meio de estratégias variadas. Entre elas, a divulgação das atividades da trupe, com a oferta de cupons-convites aos leitores, numa tentativa de formação e

2Pesquisas acadêmicas sobre revistas de teatro históricas têm sido desenvolvidas na França por um grupo da Universidade Sorbonne Nouvelle - Paris 3, sob a coordenação do professor Marco Consolini. Entrei em contato com o grupo durante período de estudos na França, no âmbito do Programa Institucional de Bolsas de Doutorado Sanduíche no Exterior (PDSE), da Capes. 
fidelização de plateias: "No público em vias de constituição, os leitores de Bref constituem o 'pelotão de choque', uma vanguarda que deve puxar a massa mais flutuante" (Loyer, 1997, p.135-136) ${ }^{3}$.

A prática de convidar os leitores para as pré-estreias dos espetáculos instaurava uma relação direta da companhia com o público provocando, inclusive, uma espécie de "curto-circuito" da crítica especializada, ausente das páginas do periódico (Loyer, 1997, p.131-133). Em seu lugar, colocava-se o julgamento feito pelos próprios espectadores, em seção dedicada às cartas dos leitores ou em artigos que faziam a compilação de seus comentários sobre os espetáculos, contendo elogios, mas também repreensões. A consulta regular ao público era igualmente feita por meio de questionários, cujas respostas eram publicadas em Bref e revelavam seus hábitos, gostos e percepções teatrais, num interessante delineamento sociológico de seu perfil.

Dar voz ao público constituía, portanto, uma forma de com ele firmar vínculo e de colocar em prática uma das mais caras concepções de Jean Vilar: "O público primeiro. O resto sempre vem depois" (Vilar apud Loyer, 1997, p.119). A companhia buscava de muitas maneiras uma relação de proximidade com seus espectadores, 0 que se tornava emblemático na frequente publicação de cartas que Vilar endereçava aos leitores do jornal. Esses escritos, que justificavam escolhas artísticas e anunciavam mudanças na organização da companhia, iniciavam-se sempre com a seguinte fórmula sugestiva de intimidade: "Queridos amigos leitores".

Fazer com que os espectadores se achegassem à companhia justificava, em parte, o próprio tom de autocelebração de Bref, perceptível tanto em seções dedicadas a apresentar a biografia de cada um dos componentes da trupe (atores e técnicos) como também em textos que anunciavam novas conquistas ou compartilhavam dores e perdas, tais como o falecimento de algum dos membros da companhia. Assim, o periódico era uma ferramenta que visava "tornar o trabalho do teatro familiar aos espectadores, fazer participar o público dos esforços do TNP em tornar o teatro acessível a todos" ("Desde o 1ำ final de semana de Suresnes instaurou-se o diálogo com o público", Bref, n. 55, abr. 1962) 4 .

\section{A missão de um teatro nacional}

O nomeado desejo de "tornar o teatro acessível a todos", além de evidenciar o compromisso com o público, remete a outro traço marcante da história do TNP, relativo à missão que orientou em grande medida sua aventura teatral. Os fundamentos da empreitada estavam ancorados nas obrigações próprias a um teatro público nacional - lembre-se que, após a Comédie Française e o Théâtre de l'Odéon, o TNP foi o terceiro teatro nacional da França.

Nesse sentido, Bref constituía uma espécie de veículo de prestação de contas e transparência de uma empresa teatral subvencionada. Em alguns de seus números,

\footnotetext{
${ }^{3} \mathrm{~A}$ tradução do trecho é minha, bem como de todas as citações extraídas de obras consultadas em francês ao longo do artigo.

4 Pelo grande número de citações a trechos extraídos de Bref, opto por citá-los desta forma, no corpo do texto, com título do artigo traduzido por mim, número da revista, mês e ano de publicação.
} 
encontramos detalhados balanços, com dados extremamente concretos sobre a frequentação das salas, as atividades realizadas e as rendas geradas. Tratava-se de justificativa pública para os subsídios estatais recebidos, além, é claro, de instrumento de luta por reconhecimento. Afirmava Vilar: "Resta muito a fazer. Que possamos receber o encorajamento esperado e necessário, que constituirá o aumento - bem legítimo, parece - dos meios colocados à nossa disposição" ("O TNP serviço público", Bref, n. 3, fev. 1957).

Eis que retorna a já citada noção vilariana de "teatro serviço público", sustentada numa lógica de triangulação entre o TNP, o Estado e o público (Loyer, 1997, p.49). Se a subvenção do Estado visava permitir a redução dos preços dos ingressos - e, de fato, os valores cobrados pelo TNP eram módicos - , a triangulação citada também se referia a algo muito mais extenso. No pós-guerra, a política da Liberação encarregaria o Estado de criar as condições de reconstrução da nação, no âmbito da qual a cultura desempenharia um papel fundamental. $O$ "teatro serviço público" seria, desse modo, portador da consciência de seus deveres cívicos.

O próprio emblema da trupe confirmava isso, como se lê em artigo publicado em Bref e assinado por Marcel Jacno, o criador do logotipo: "Inscrito numa forma oval, onde se encontra, em todas as letras, o nome do Teatro Nacional Popular, o conjunto tornou-se semelhante a um selo de administração pública. O carimbo TNP estava criado" ("As proclamações do ano III nos cartazes do TNP", Bref, n. 16, maio 1958) ${ }^{5}$. Em geral, a marca do grafismo de Jacno para o TNP, por sua austeridade, lisibilidade e coloração, fazia lembrar a Revolução Francesa, imitando o estilo dos cartazes da Constituinte e das proclamações de Napoleão Bonaparte.

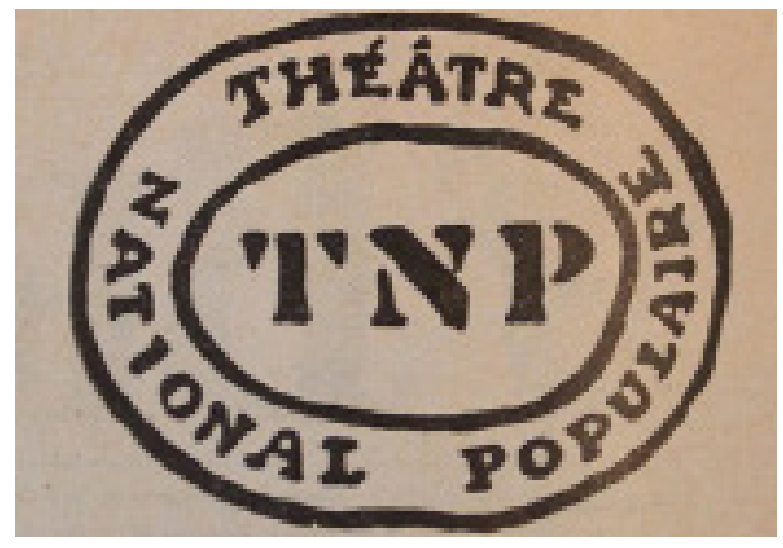

Figura 1. Emblema do Teatro Nacional Popular estampado em Bref. Fotografia de Mariana Oliveira.

Esse era, portanto, o símbolo de um teatro que representava a nação. Essa função também ficava evidente nas ocasiões das turnês mundiais do TNP, documentadas em Bref. Nessas viagens, diz-se que a trupe encarnava o papel de verdadeiro "embaixador da França no estrangeiro" (Loyer, 1997, p.53). Outro sinal dessa identi-

50 título faz referência à Revolução Francesa, que estabeleceu um novo calendário, contando os anos a partir da proclamação da República, em 1792. 
ficação do TNP com a nação estava no repertório dramático escolhido, com clara predominância de autores franceses, conforme se percebe folheando as páginas do jornal que tratam dos espetáculos da companhia. Durante o período sob direção de Vilar (1951-1963), de um total de 57 peças montadas, 37 eram francesas (Loyer, 1997, p.38; 176). Na triangulação com o público e o Estado, portanto, a missão comprometida com a imagem desse último constituía traço forte do TNP.

\section{Concepção humanista do teatro}

A questão do repertório encenado evoca ainda outro importante aspecto do TNP também confirmado por meio da análise de Bref. Vale especificar que, das 37 peças francesas mencionadas acima, 24 eram textos clássicos (Loyer, 1997, p.38; 176). Isso refletia, em parte, a herança artística que o TNP recebera dos ditos "teatros de arte" franceses, cujas personalidades-chave, tais como Charles Dullin e Jacques Copeau, eram assuntos frequentes nos textos do periódico. Vilar havia sido aluno de Dullin e, esse, braço direito de Copeau, que acreditava na necessidade da volta às obras primas do passado como estratégia para "provocar a inteligência do público", dando-lhe "alimento espiritual" (Caune, 1992, p.76). Na mesma direção, Vilar visava despertar "nas classes populares o gosto adormecido do saber e do conhecimento através do teatro" (Vilar, 1975, p.241).

Ora, outra herança histórica do TNP, igualmente presente nas páginas do jornal, era justamente o ideário da educação popular que, desde o século XIX, baseava-se na crença de que o conhecimento leva à libertação individual e coletiva. O próprio Vilar o afirmava: "Teatro popular significa aprender; e aprender: liberar o homem" (1975, p.252). Esses conceitos conduziam, assim, à preconização da difusão e do compartilhamento dos bens culturais, num processo de democratização da cultura reforçado no pós-guerra francês, quando a aspiração de reconstrução da nação sobre bases humanistas se traduziria no ideal enunciado pelo Conselho Nacional da Resistência de dar a cada cidadão "o direito à cultura mais desenvolvida" (Loyer, 1997, p.102).

A luta contra as desigualdades culturais e a busca pelo compartilhamento da cultura fundavam uma nova responsabilidade de Estado, legatária de ideais do Iluminismo e da Revolução Francesa e fundamentada numa concepção de cultura universal que equivalia a uma "cultura no singular que diz respeito ao Homem em geral" (Loyer, 1997, p.109-110). Tratava-se da alta cultura, a das obras primas vistas como eternas e universais, constituintes do patrimônio da humanidade.

Imbuído das questões sociais de seu tempo, portanto, Vilar, que gozava de liberdade para escolher as peças que montaria, optava por um repertório de alta cultura por acreditar em sua universalidade: "O teatro popular significa teatro universal. O Cid é teatro popular porque O Cid faz sucesso em todo lugar" ("Jean Vilar se explica...", Bref, n. 7, out. 1955). Sua função como encenador era atualizar esses textos para uma sensibilidade contemporânea e atingir, enfim, um público que deles tinha estado por muito tempo privado (Caune, 1992). Eis aí, afinal, dois preceitos primordiais do teatro popular vilariano, segundo Roland Barthes: "um público de massa" e "um repertório de alta cultura" (Barthes, 2002, p.99). 


\section{Ações para a democratização da cultura}

Para unir as duas pontas do movimento de democratização da cultura, isto é, o público de massa e o repertório de alta cultura, ações concretas foram necessárias. $\mathrm{Na}$ análise de Bref, é possível identificar algumas delas. Antes de tudo, vale mencionar a notória simpatia pela política da descentralização teatral, implementada na França na década de 1940 pelo ministério da Educação nacional através da pessoa de Jeanne Laurent, que tem artigo publicado no jornal, junto a outros assinados pelos diretores dos primeiros Centros Dramáticos Nacionais.

No que diz respeito às ações específicas desempenhadas pelo próprio TNP, Bref traz notícia sobre as turnês pela periferia de Paris (1951-1957), cujos propósitos eram explicitados em texto de Jean Vilar: "Não é só questão de ir provar aos habitantes das cidades da periferia que esse teatro, feito para eles, não lhes é inacessível, nem pelo preço dos ingressos, nem pelas obras representadas. Trata-se de tornar o fato teatral novamente familiar e necessário para eles" ("O TNP na periferia", Bref, n. 4, mar. 1957).

A democratização da cultura implicava facilitar o acesso do público ao evento teatral: além dos baixos preços dos ingressos, outras medidas de "desaburguesamento" do ritual de ida ao teatro foram tomadas pelo TNP, conforme Jean Vilar pontuou em Bref: "Em cinco anos, o TNP não cessou de multiplicar em benefício de seu público as facilidades [...] de acolhimento (espetáculos às 20 horas, supressão das gorjetas, gratuidade dos vestiários, fechamento das portas a partir do início da representação, e retransmissão dessa para os retardatários por vídeo-televisão, etc..." ("O TNP serviço público", Bref, n. 3, fev. 1957).

Mais que facilitar o acesso, a trupe investiu em métodos de busca ativa de público, por meio, por exemplo, de pesquisas por telefone, por correspondência ou por visita direta, num conjunto de estratégias que acabaria por mostrar bons resultados: em 1963, Vilar deixaria a direção de um TNP que se apresentava na maior parte das vezes com as bilheterias fechadas e com a sala ocupada, em algumas ocasiões, até mesmo acima de sua capacidade. Na composição do público, sobressaía a presença jovem, como decorrência da prioridade dada a essa parcela da população nas ações de formação de plateia (Loyer, 1997). Sobre isso, Bref traz abundantes informações.

\section{A mediação com o mundo escolar}

Acerca das relações que o TNP desenvolveu, através dos anos, com o meio escolar, vale notar, antes de tudo, que o próprio diretor de publicação de Bref e administrador da trupe, Jean Rouvet, era educador (Loyer, 1997). Além disso, no periódico, é possível perceber o destaque que os estabelecimentos escolares mereceram na rede de correspondentes do TNP. Esse lhes enviava regularmente uma documentação completa sobre suas atividades, entre as quais figuravam as matinês estudantis. Vilar comentou o assunto em Bref: "Nós montamos apenas os 'clássicos' do repertório. A programação das matinês clássicas é enviada, assim que estabelecida, a todos os provisores, diretores e professores do ensino secundário e técnico, e aos centros de aprendizagem, às vezes com recomendações (para Fedra...); de acordo com os gêneros, às vezes é feito um envio especial aos professores de Inglês, por exemplo, 
quando vamos montar um Shakespeare..." ("O espírito e o literal", Bref, n. 16, maio 1958).

O repertório da companhia, nas matinês estudantis, buscava dialogar com o conteúdo programático escolar e garantir, assim, a adesão dos professores. Interessante observar que os escritos de espectadores em Bref faziam constante referência à escola, numa configuração do teatro como "prolongamento da experiência escolar" e como "instrumento de conhecimento" (Loyer, 1997, p.144). Além disso, textos de autoria de professores eram publicados, confirmando de maneira mais decisiva a relação positiva do universo escolar com o TNP e sua aprovação por parte daqueles profissionais. Um deles, Pierre Descazaux, exprimiu com clareza o pensamento de uma parcela engajada dos professores, comprometida com a ideia da democratização da cultura, marca forte do próprio TNP, como já discutido: "Para nós, que conhecemos bem esse meio social [de operários, empregados, artesãos e pequenos funcionários] e melhor ainda o meio escolar que ele oferece à nossa atividade de educadores, o Teatro Nacional Popular mostrou-se muito cedo como um encontro de importância capital ao qual nós devemos ser fiéis" ("A adolescência e o teatro", Bref, n. 55, abr. 1962).

No tocante aos alunos, seus pontos de vista favoráveis ao TNP também se faziam frequentemente representar em Bref, assim como sua participação nos Encontros Internacionais de Jovens em Avignon, criados em 1955 com o intuito de "tornar mais fácil o acesso dos jovens espectadores ao Festival" ("Encontros Internacionais de Jovens em Avignon", Bref, n. 23, fevereiro 1959). Esse projeto alcançou grande sucesso, com 500 a 1.000 inscritos anualmente, premiando a forte mobilização do TNP nesse sentido, conforme explicitado por Vilar: "Eu não sei que outro teatro no mundo tem feito esforço similar para os estudantes" ("Quatro novas direções", Bref, n. 29 , out. 1959).

\section{A dimensão educativa}

A dimensão educativa do TNP não se restringia às relações com o meio escolar, com os estudantes ou com a juventude, conforme revela a análise de Bref. A companhia adotou uma série de procedimentos que iam em direção a uma espécie de educação do público, no contexto do desejo de "renovação estética de uma arte pervertida pelo século burguês" e de "conquista de um novo público popular que desertou as salas de teatro" para ir ao cabaré ou ao café-concerto (Loyer, 1997, p.6).

Por exemplo, vemos, em Bref, anúncios de livros-programas que traziam os textos completos dos espetáculos encenados pelo TNP e compunham a chamada "coleção do repertório". Vendidos a um preço muito baixo, constituíam uma verdadeira ferramenta para a construção de referências para uma cultura teatral, do mesmo modo, aliás, que a própria Bref. Embora feita em papel jornal e formato A3, objeto difícil de guardar por muito tempo, a publicação trazia regularmente numerosos textos teóricos sobre as peças montadas pela trupe, numa variada gama de abordagens: biografias de autores, resumos da ação das peças, descrições dos contextos de sua escritura, perspectivas históricas de diferentes encenações, análises assinadas por especialistas, discussões acerca de conceitos teatrais. 
Ao longo de todo um ano (1957-58), Bref também publicou uma curiosa seção chamada "Os jogos do teatro", propondo um desafio aos leitores: "Bref oferece-lhes hoje a chance de colocar à prova sua cultura teatral divertindo-se". Seguiam-se palavras-cruzadas, criptogramas, charadas, questões do tipo "Você sabia?" e jogos iconográficos, tais como: "Você pode identificar esta foto de um espetáculo de Pirandello (título da peça, teatro, ano de criação, personagens, encenador)?" ("Os jogos do teatro", Bref, n. 7, jun. 1957). Prêmios eram oferecidos: ingressos para espetáculos do TNP, livros de Vilar, volumes da coleção do repertório ou mesmo a assinatura de Bref para aqueles que tivessem atingido o menor número de pontos nos jogos - talvez para que pudessem, assim, conquistar os conhecimentos de que careciam.

\section{Bref, papéis multiplicados}

Bref, o jornal mensal do TNP, mostra-se, afinal, rico objeto de estudo. Se, na época de sua publicação na França, cumpria diversas funções na trajetória de estabelecimento e consolidação de trabalho de uma companhia teatral imbuída de concepções e metas bem delineadas, hoje, tem seu interesse renovado não só pela perspectiva histórica de reconstituição dos modos de atuação do TNP de Jean Vilar, mas também pela potencialidade em fazer refletir acerca de temas muito atuais.

Analisada sob os seis pontos elencados neste texto (relação com o público, missão de um teatro nacional, concepção humanista do teatro, ações para a democratização da cultura, mediação com o mundo escolar e dimensão educativa), Bref suscita reflexões de grande amplitude tais como as relações que o teatro pode estabelecer com a sociedade e com a educação, a responsabilidade dos artistas para com essas últimas e do Estado para com as artes. Em termos mais precisos, essas reflexões podem desdobrar-se em questões como a da mediação entre a arte teatral e seu público, a da democratização do acesso ao teatro e a da formação de espectadores.

Ao permitir tudo isso, a análise de Bref exemplifica como um periódico sobre teatro, que, sob uma primeira mirada, poderia ser considerado de valor efêmero e circunscrito, pode multiplicar-se em seus papéis. Numa espécie de jogo de espelhos, a publicação que ora o leitor tem diante de seus olhos apresenta, neste texto, o tema do jornal mensal do TNP, que, por sua vez, reflete a imagem do teatro de que era porta-voz, remetendo a uma série de discussões que ultrapassam os limites da publicação histórica e apontam para a temática geral das possíveis funções de um periódico que deseja colocar em questão o teatro de seu tempo.

\section{Referências}

BARTHES, Roland. Pour une définition du théâtre populaire. In: Écrits sur le théâtre. Paris : Éditions du Seuil, 2002.

BREF, Journal Mensuel du Théâtre National Populaire. Paris: Théâtre National Populaire, n. 1-68, déc. 1956 - juin-juill. 1963. 
CAUNE, Jean. La culture en action. De Vilar à Lang: le sens perdu. Grenoble: Presses Universitaires de Grenoble, 1992.

DESGRANGES, Flávio. A pedagogia do espectador. São Paulo: HUCITEC, 2010.

LOYER, Emmanuelle. Le théâtre citoyen de Jean Vilar. Une utopie d'après-guerre. Paris: Presses Universitaires de France, 1997.

PUPO, Maria Lúcia de Souza Barros. Para alimentar o desejo de teatro. Revista Sala Preta, v. 9, n. 1, p. 269-278, 2009, ISSN 2238-3867. Disponível em: http://revistas.usp. br/salapreta/article/view/57411/60393 Acesso em: 16 mar 2014, 14:30.

Mediação artística, uma tessitura em processo. Revista Urdimento, n. 17, p. 113-121, Setembro, 2011, ISSN 1414-5731. Disponível em: http://www.ceart.udesc. br/ppgt/urdimento/2011/index_17.html. Acesso em: 16 mar 2014.

VEINSTEIN, André. Du théâtre libre au théâtre Louis Jouvet. Les théâtres d'art à travers leur périodique (1887-1934). Paris: Éditions Billaudot, 1955.

VILAR, Jean. Le théâtre, service public. Paris: Gallimard, 1975.

Recebido em: 14/05/2014 Aprovado em: 21/08/2014 